\title{
Editorial for the Special Issue for the 3rd Modern Solid Phase Peptide Synthesis and its Applications Symposium
}

\author{
Neil M. O’Brien-Simpson · John D. Wade
}

Published online: 3 February 2013

(c) Springer Science+Business Media New York 2013

In the Spring of 1962 Professor Bruce Merrifield gave his first public description of the concept of solid phase chemistry for the synthesis of peptides at the Federation of the American Societies for Experimental Biology (FASEB) annual meeting. Fifty years on, some of the latest developments in solid phase peptide chemistry were reported at the 3rd Modern Solid Phase Peptide Synthesis and its Applications Symposium that was held at Daydream Island in Queensland, Australia, from 13th to 16th October, 2011. The symposium, an official satellite meeting of the 9th Australian Peptide Conference, and originally conceived 6 years earlier by Professor John Wade (Symposium Chairperson) has the goal of bringing together academic and industrial scientists to present and discuss the latest developments in solid phase peptide chemistry. The symposium attracted over a hundred delegates from around the world who described the synthesis and use of new and novel resins and reaction parameters to produce peptides of a high yield and purity. The field of solid phase peptide chemistry is ever expanding and the symposium aimed to capture these advances in SPPS and through the invited speakers (Paul Alewood, Brian Chia, Mike Gait, Ralf Hoffman, Knud Jensen, Lei Liu, John McMurray and James Tam) to stimulate interest and discussion in research into the synthesis of post-translationally modified peptides, microwave assisted chemistries, peptidomimetics and

N. M. O’Brien-Simpson ( $₫)$

Melbourne Dental School, Oral Health CRC, The University

of Melbourne, Melbourne, VIC, Australia

e-mail: neil.obs@unimelb.edu.au

\section{J. D. Wade}

Howard Florey Institute, The University of Melbourne,

Melbourne, VIC, Australia

e-mail:wade@hfi.unimelb.edu.au therapeutics, oligonucleotide analogues and ligation chemistries for inducing structure and/or protein synthesis.

The opening plenary session given by James Tam and Paul Alewood on "Tandem acyl shifts for preparing peptide thioesters for Fmoc chemistry" and "Folding miniproteins", projected the symposium into a series of lively and enthusiastic discussions which continued for the whole symposium and made for new scientific insights and collaborations. The scientific program covered the major themes in SPPS with sessions which included "SPS of peptidomimetics", "SPPS Methodology", "SPS of antimicrobial peptides", "Microwave assisted SP biomolecule synthesis", "APPS-biological applications" and "Solid phase protein synthesis". Once again oral presentations were complemented by an evening poster session and dinner to encourage further discussions and collaborations. The success and continuation of the meeting has many parts and contributions and the organising committee would like to thank the financial support provided by and participation of several major sponsors including the Australian Peptide Association.

The previous two Modern Solid Phase Peptide Synthesis and its Applications Symposia generated considerable excitement that resulted in Special Issues of the International Journal of Peptide Research and Therapeutics. The third meeting was no different and after the meeting delegates were invited to submit an article on their work and that that captured the essence of the meeting. This special issue brings together a collection of fully peer-reviewed articles on all of the areas covered in the meeting and demonstrates why the Modern SPPS meeting generates such scientific anticipation and excitement amongst the delegates. We would like to thank each of the contributing authors for their patience and cooperation in making this special issue possible. We are also very grateful to all of 
the referees who agreed and then quickly reviewed these articles and to Ms Geetha Subramanian from the Editorial Office at Springer Publishing. Our thanks also to Anand Chozhan (Anand Manimudi Chozhan) of Springer for his excellent copyediting of this special issue. The delegates deserve a special thank you as without their support for this meeting it would not be so enjoyable. The continued success of this third meeting has led to the 4th Modern Solid Phase Synthesis and its Applications Symposium being scheduled for the 2-5th November at the Seaside Hotel, Maiko Villa, Kobe in Japan immediately preceding the 4th Asia-Pacific Peptide Symposium (APIPS) that will be held in Osaka from 6th to 8th November, 2013. For details of this meeting, please go to www.solidphase.org. 